\title{
Seed Germination and Seedling Growth of the Endangered Azorean Cherry Prunus azorica
}

\author{
Orlanda Cristina Barros Moreira ${ }^{1}$, José Martins, Luís Silva, \\ and Mónica Moura \\ CIBIO, Centro de Investigação em Biodiversidade e Recursos Genéticos, \\ InBIO Laboratório Associado, Pólo dos Açores, Departamento de Biologia, \\ Universidade dos Açores, 9501-801 Ponta Delgada, Portugal
}

Additional index words. Azores, conservation, dormancy, endemic, Prunus azorica, seed germination, seedling growth

\begin{abstract}
Prunus azorica is an Azorean endemic tree considered as a priority species for conservation. It is important as a laurel forest component, particularly at medium altitude, and as a food source for the endangered bird Pyrrhula murina. The best conditions for seed germination were investigated after removal of the outer layers of the fruit by determining the effect of 1 ) using stones or seeds; 2) stratification regime (six treatments and a control); 3) incubation temperature (four alternating temperature regimes); and 4) gibberellic acid concentration (three levels). This resulted in a fully factorial design with $168(2 \times 7 \times 4 \times 3)$ treatments with three replicates per treatment and 25 seeds per replicate. Cumulative germination percentages were determined at the end of the trial. Globally, there was a significant effect of endocarp removal $(49 \%$ germination with seeds and $15 \%$ with stones). Both for stones and seeds, there was a significant effect of incubation temperature, stratification regime, and growth regulator concentration. Stones attained a maximum germination of $\approx \mathbf{8 0} \%$ under several stratification treatments including cold $\left(4^{\circ} \mathrm{C}\right)$ or warm $\left(20^{\circ} \mathrm{C}\right)$ followed by cold and at $10 / 5^{\circ} \mathrm{C}$ without the addition of a growth regulator. Seeds attained a maximum germination of greater than $90 \%$ without stratification at $10 / 5$ or $15 / 10{ }^{\circ} \mathrm{C}$ without the addition of a growth regulator. During the stratification process, germination occurred only for seeds, particularly for longer treatments, for example, those corresponding to 3 or more months of stratification, including warm followed by cold $(75 \%$ to $80 \%)$ or cold alone $(77 \%)$. According to seed morphology and germination results, the seed appears to have a non-deep physiological dormancy. Seeds of $P$. azorica can thus be efficiently germinated after endocarp removal at temperatures of $10 / 5$ or $15 / 10{ }^{\circ} \mathrm{C}$ with a daily light period of 12 hours. This protocol allowed producing hundreds of viable seedlings that were used in the reforestation of a laurel forest stand in a LIFE project.
\end{abstract}

Prunus azorica (Hort. ex Mouillef.) Rivas Mart., Lousã, Fern. Prieto, E. Dias, J.C. Costa, and C. Aguiar, commonly named Azorean cherry or "ginja-do-mato," is an endangered tree endemic to the Azores, Portugal. It is currently found in São Miguel, Terceira, São Jorge, Pico, Faial, and the Flores islands (Cardoso et al., 2008; Martins et al., 2008; Schäfer, 2005; Silva et al., 2009). It is usually a small tree or shrub, rarely above $4 \mathrm{~m}$ tall. However, in sheltered locations (such as water stream margins), it is able to attain height greater than $10 \mathrm{~m}$. It occurs at altitudes above $500 \mathrm{~m}$, mainly in craters and deep narrow ravines, or scattered in undisturbed hyperhumid native forest (Silva et al., 2009). This species has become very rare and recently, only scattered individuals were found in São Miguel and Pico, whereas in Flores, only one individual is known to exist. Considered as one of the top 100 priority taxa for

Received for publication 1 Mar. 2012. Accepted for publication 26 June 2012.

${ }^{1}$ To whom reprint requests should be addressed; e-mail orlandamoreira@uac.pt. by cuttings. However, in cases of depauperated populations and to maintain the genetic variability of the population, propagation by seeds might be preferable (Barrett and Kohn, 1991). Until recently, germination of $P$. azorica was based on empirical knowledge, leading to relatively low germination percentages and to the demand for large numbers of seeds to produce a desired quantity of growing stocks, which further deplete the natural populations' seed stock. Previous studies by the Azorean Forest Service using seeds collected in September/October and germinated in trays inside a greenhouse reported a germination percentage of $\approx 50 \%$ (Fagundo and Isidoro, 2004). Additionally, there was no knowledge on the different factors that might affect the germination of this species. Maciel (1995, 1996), when failing to promote germination of $P$. azorica seeds, suggested the occurrence of a dormancy connected to inhibitory mechanisms located at the embryo and seedcoat; however, no further experiments were conducted.

Dormancy is a condition in which seeds do not germinate even when the environmental conditions are favorable for germination (Baskin and Baskin, 2004; Bewley and Black, 1994; Hartmann et al., 1997; Nicolaeva, 1977). In several Prunus species, seed dormancy is considered as an adaptive mechanism to protect fruit trees from freeze damage during the winter (Martynez-Gómez and Dicenta, 2001). However, the occurrence of seed dormancy can become a significant hindrance in cases of endangered taxa, preventing the possibility of fast production of a large number of seedlings for reintroduction in the native populations (Moura and Silva, 2010).

Some prunoid species have fruits with a stony endocarp and embryos with deep physiological dormancy, requiring long periods of cold stratification for dormancy break (Crocker and Barton, 1931; Flemion, 1934; Nicolaeva, 1969, 1977). There is a considerable variety of methods that can be used for dormancy-breaking and seed germination among different Prunus species (Ellis et al., 1985; Finch-Savage et al., 2002; Grisez, 1974; Suszka, 1962). Cherries generally have deep dormant seeds and in wild cherry $(P$. avium), a deep and variable embryo dormancy is the most significant germination inhibiting factor, which requires a very complex moist stratification regime with consecutive warm and cold periods, imitating the end of summer or fall, to break dormancy (Esen et al., 2006; Finch-Savage, 2001; Grisez, 1974; Suszka, 1967, 1990). Inversely, long periods at constant high temperatures during stratification and germination tests induced secondary seed dormancy in the same species (Esen et al., 2009). Grisez (1974) referred a requirement of 3 to 4 months of cold stratification to overcome embryo dormancy in cherry seeds. Experimental comparisons among various stratification temperatures for several species showed that constant temperatures from 2 to $5{ }^{\circ} \mathrm{C}$ are more favorable than those below $1.7^{\circ} \mathrm{C}$ or above $8{ }^{\circ} \mathrm{C}$ (Coe and Gerber, 1934; Crocker and Barton, 1931; 
Haut, 1938). However, warm stratification before cold stratification might be needed in cases of underdeveloped embryos (FinchSavage, 2001; Finch-Savage et al., 2002).

Addition of gibberellins was also shown to increase germination percentage in Prunus species (Carrera et al., 1988; Giba et al., 1993; Karam and Al-Salem, 2001). Gibberellin $\left(\mathrm{GA}_{3}\right)$ treatments can replace a portion of the stratification period in several Prunus spp., but only after endocarp removal (Grisez et al., 2003). Likewise, $\mathrm{GA}_{3}$ addition promoted the germination of non-stratified $P$. campanulata seeds after endocarp removal (Chen et al., 2007) and significantly increased the germination percentages of $P$. avium and $P$. serotina seeds (Çetinbas and Koyuncu, 2006; Phartyal et al., 2009).

Regarding incubation temperature, an alternating temperature regime (daily oscillation between a high and a low value) during germination trials has enhanced seed germination percentages not only in Prunus spp. (Suszka, 1962), but also in other Azorean woody species (Martins et al., 2012; Moura and Silva, 2010).

The present study aims to determine which treatments are able to break the dormancy of $P$. azorica seeds and to increase the germination percentage and speed, improving the efficiency of its propagation. Besides testing those factors that might affect germination and lead to dormancy break, following seedling development after radicle emergence might also be important to determine the type of seed dormancy, namely the epicotyl dormancy classification (Baskin and Baskin, 1998). For that, 1) the effect of several pretreatments on seed germination percentage was evaluated, including endocarp removal, stratification regime, growth regulator concentration, and incubation temperature; and 2) initial seedling development was followed.

\section{Materials and Methods}

Sampling and treatment of fruits. Ripe drupes (dark red) were harvested at the end of September, in the largest known population of this species, located in the northeast of São Miguel Island, Azores, from randomly selected adult non-consecutive trees. Shriveled and unusually small fruits were discarded from the samples. The pulp (exocarp and mesocarp) was manually removed in all the fruits. The fruits were hand-crushed in a plastic bowl, releasing the stones (endocarp and seed) from the pulp, which were transferred to a metal strainer and washed under running tap water, removing the pulp and surfacecleaning the stones. Extracted stones were briefly immersed in distilled water (less than $30 \mathrm{~s})$ to separate sound seeds and were then placed on paper to absorb excess water and dried at room temperature for $2 \mathrm{~d}$ (Esen et al., 2006).

Embryo characteristics, seed viability, and water imbibition. To evaluate the developmental stage of the embryo, total seed length and embryo length (including primordial leaves) were measured on a sample of 90 randomly selected seeds. To verify seed viability, a sample made of three replications of 30 seeds from all seed stocks and was subjected to the tetrazolium testing protocol as defined by the Association of Official Seed Analysts (2007). Seed moisture contents before the beginning of the pretreatments were calculated using International Seed Testing Association rules for seed testing (ISTA, 1996). To determine water imbibition capacity of the stones and seeds, $3 \times 30$ of intact dry stones and $3 \times 30$ seeds were weighed, immersed in distilled water, and reweighed after 1, 6, 24, 72, and $144 \mathrm{~h}$. Stones were opened and weighed (endocarp and seed separately) to compare seed imbibition when naked or covered by the endocarp.

General test conditions. Germination tests were performed in chambers with automatic temperature control (error margin of $\approx 1{ }^{\circ} \mathrm{C}$ ) and a light period of $12 \mathrm{~h}$ provided by six fluorescent lamps with a photosynthetic photon flux density of 19 to $22 \mu \mathrm{mol} \cdot \mathrm{m}^{-2} \cdot \mathrm{s}^{-1}$. Alternating incubation temperatures were used. Depending on the treatments, stones or seeds were placed on filter paper inside $12-\mathrm{cm}$ petri dishes. To control fungal contamination, seeds and stones were periodically washed in running tap water, transferred to clean petri dishes, and the filter paper was moistened with a $6 \%(\mathrm{w} / \mathrm{v})$ Benomyl solution.
Experimental design and treatments. The tested factors included 1) endocarp treatment (stones or seeds); 2) stratification regime (six regimes and a control); 3) incubation temperature (four alternating temperature regimes); and 4) $\mathrm{GA}_{3}$ concentration (three levels). This resulted in a fully randomized factorial design with $168(2 \times 7 \times 4 \times 3)$ treatments with three replicates per treatment and 25 seeds per replicate. In those cases in which a part of the seeds germinated during the stratification process, the remaining seeds were distributed evenly by the different treatments.

Half of the stones were hand-opened (using a stainless steel nipper) completely removing the endocarp, and the remaining stones were used as a control.

Stones and seeds were submitted to six different stratification treatments and a control, including 1) cold moist stratification at $4{ }^{\circ} \mathrm{C}$ for 30,60 , or $90 \mathrm{~d} ; 2$ ) a combination of $30 \mathrm{~d}$ warm moist stratification at $20{ }^{\circ} \mathrm{C}$ followed by cold moist stratification at $4{ }^{\circ} \mathrm{C}$ for 30,60 , or $90 \mathrm{~d}$; and 3) to a control without stratification. For each treatment, a set of 300 $(4 \times 75)$ stones or seeds was placed inside net bags kept in plastic trays $(40 \times 20 \mathrm{~cm})$ and stratified by using a mixture of perlite and peat $(1: 1)$ as a substrate. A refrigerator for cold stratification or a temperature-controlled chamber for warm stratification were used.

Table 1. Effect of stone treatment (stones/seeds), incubation temperature, stratification regime, and growth regulator concentration on the percentage of germination of Prunus azorica seeds. ${ }^{\mathrm{z}}$

\begin{tabular}{|c|c|c|c|c|c|}
\hline Source & SS & $\mathrm{df}$ & MSS & $\mathrm{F}$ & $P$ \\
\hline \multicolumn{6}{|l|}{ Global } \\
\hline Stones/seeds & 22.63 & 1 & 22.63 & 994.7 & $<0.001$ \\
\hline Incubation temperature & 29.09 & 3 & 9.70 & 426.2 & $<0.001$ \\
\hline Stratification & 4.54 & 6 & 0.76 & 33.3 & $<0.001$ \\
\hline Growth regulator concentration & 1.63 & 2 & 0.82 & 35.9 & $<0.001$ \\
\hline Stones/seeds*temperature & 1.41 & 3 & 0.47 & 20.6 & $<0.001$ \\
\hline Stones/seeds*stratification & 7.44 & 3 & 2.48 & 109.0 & $<0.001$ \\
\hline Stones/seeds* growth regulator & 0.76 & 2 & 0.38 & 16.8 & $<0.001$ \\
\hline Stratification*temperature & 3.40 & 18 & 0.19 & 8.3 & $<0.001$ \\
\hline Stratification* growth regulator & 1.92 & 12 & 0.16 & 7.0 & $<0.001$ \\
\hline Temperature* growth regulator & 1.26 & 6 & 0.21 & 9.2 & $<0.001$ \\
\hline Stones/seeds*temperature*stratification & 0.75 & 9 & 0.08 & 3.7 & $<0.001$ \\
\hline Stones/seeds*temperature* growth regulator & 0.36 & 6 & 0.06 & 2.6 & 0.018 \\
\hline Stones/seeds*stratification*growth regulator & 1.03 & 6 & 0.17 & 7.5 & $<0.001$ \\
\hline Temperature*stratification*growth regulator & 1.22 & 36 & 0.03 & 1.5 & 0.042 \\
\hline $\begin{array}{l}\text { Stones/seeds*temperature* stratification* growth } \\
\text { regulator }\end{array}$ & 1.08 & 18 & 0.06 & 2.6 & $<0.001$ \\
\hline \multicolumn{6}{|l|}{ Stones } \\
\hline Incubation temperature & 14.53 & 3 & 4.84 & 313.8 & $<0.001$ \\
\hline Stratification & 2.95 & 6 & 0.49 & 31.9 & $<0.001$ \\
\hline Growth regulator concentration & 2.87 & 2 & 1.43 & 92.9 & $<0.001$ \\
\hline Stratification*temperature & 3.64 & 18 & 0.20 & 13.1 & $<0.001$ \\
\hline Temperature*growth regulator & 1.98 & 6 & 0.33 & 21.4 & $<0.001$ \\
\hline Stratification* growth regulator & 0.82 & 12 & 0.07 & 4.4 & $<0.001$ \\
\hline Temperature*stratification* growth regulator & 1.46 & 36 & 0.04 & 2.6 & $<0.001$ \\
\hline \multicolumn{6}{|l|}{ Seeds } \\
\hline Incubation temperature & 14.13 & 3 & 4.71 & 132.4 & $<0.001$ \\
\hline Stratification & 9.03 & 3 & 3.01 & 84.6 & $<0.001$ \\
\hline Growth regulator concentration & 0.28 & 2 & 0.14 & 4.0 & 0.022 \\
\hline Temperature*stratification & 0.51 & 9 & 0.06 & 1.6 & 0.124 \\
\hline Temperature*growth regulator & 0.16 & 6 & 0.03 & 0.8 & 0.606 \\
\hline Stratification* growth regulator & 2.13 & 6 & 0.35 & 10.0 & $<0.001$ \\
\hline Temperature*stratification*growth regulator & 0.84 & 18 & 0.05 & 1.3 & 0.202 \\
\hline
\end{tabular}

${ }^{\mathrm{z} R e s u l t s ~ o f ~ a ~ m u l t i f a c t o r i a l ~ a n a l y s i s ~ o f ~ v a r i a n c e ~ a p p l i e d ~ t o ~ a l l ~ t h e ~ d a t a ~(G l o b a l), ~ o r ~ o n l y ~ t o ~ t h e ~ t r e a t m e n t s ~}$ using stones (Stones) or seeds (Seeds).

$\mathrm{SS}=$ sum of squares; MSS = mean sum of squares. 
The effect of growth regulator concentration was tested by immersing the seeds and stones in distilled water (control) or in two solutions of 250 or $500 \mathrm{mg} \cdot \mathrm{L}^{-1} \mathrm{GA}_{3}$ for $24 \mathrm{~h}$.

To determine the effect of incubation temperature, seeds and stones were incubated at four different alternating temperatures: $10 / 5$, $15 / 10,20 / 15$, and $25 / 20{ }^{\circ} \mathrm{C}$. Those values were based on the mean temperatures for each season of the year estimated for $P$. azorica natural habitat by the CIELO model (Azevedo, 1996). Stratified seeds or stones were incubated at the four alternating temperatures at different times as the stratifications treatments ended. Non-stratified seeds or stones (control) were incubated immediately, coinciding with the beginning of the stratification treatments.

Germination, corresponding to visible radicle emergence $(\approx 2$ to $3 \mathrm{~mm}$ long), was monitored at weekly intervals for 24 weeks.

Seedling growth. After radicle emergence, seedling development was followed until the emergence of the third leaf pair. Three replicates of 30 germinated seedlings in the same development stage were randomly selected from all the different germination treatments, planted in peat disks, and maintained in plastic bottles in a nursery at $20{ }^{\circ} \mathrm{C}$ (the approximate average temperature in spring, when germinated seedlings can be found in nature) under a daily light period of $16 \mathrm{~h}$. The seedlings were observed every other day and the number of days for emergence of the first, second, and third pairs of leaves were recorded. Height was measured after the emergence of the third pair of leaves and the plantlets were then transferred to $500 \times 300$-mm trays composed of 40 individual cells with a substrate volume of $300 \mathrm{~cm}^{3}$ and kept in an outdoor shaded greenhouse with manual irrigation.

Statistical analysis. Average germination percentage for each treatment was calculated after 24 weeks of incubation. Percentages were transformed using arsine[square-root (x)] and normality was determined with the Kolmogorov-Smirnov test (Zar, 1999). A multiway analysis of variance (ANOVA) was used to determine the main effects and interactions of all tested factors on the germination percentage, including: 1) stones vs. seeds (two levels); 2) stratification (seven levels); 3) temperature (four levels); and 4) $\mathrm{GA}_{3}$ (three levels). The ANOVA was initially applied to the global data. Because several significant interactions were found among the tested factors, and to determine possible differences in the response of seeds and stones, the same procedure was applied 1) to the data regarding stones only; and 2) to the data regarding seeds only. In addition, to better determine the influence of incubation temperature and growth regulator concentration in non-stratified seeds, a two-way ANOVA was applied to that specific fraction of the data. A Tukey honestly significant difference test was used as a multiple comparison procedure. In relevant cases, namely the best treatments, variation in germination was displayed with germination curves and the
Gompertz sigmoid function (Gompertz, 1825; Laterra and Bazzalo, 1999) fit to the data for calculation of the expected germination values and of the $T_{50}$ values (i.e., the time taken for germination percentages to reach $50 \%$ ). Rate of water imbibition was compared in stones and seeds, namely by calculating the total percent of increase in weight and the per-hour rate of increase. Final weight of seeds inside stones and of naked seeds (endocarp removed) was compared using a $t$ test. Statistical analyses were performed using SPSS 15.0 (SPSS Inc., Chicago, IL) and Microsoft Office Excel 2003 (Microsoft Inc., Redmond, WA).

\section{Results}

Embryo characteristics, seed viability, and water imbibition. Embryos were spatulate with large cotyledons; mean seed length was $7.51 \pm 0.09 \mathrm{~mm}$ (mean $\pm \mathrm{SE})$, and mean embryo length, without cotyledons and including first true leaves, was $2.34 \pm 0.039 \mathrm{~mm}$. Tetrazolium test showed a viability of $100 \%$ of the tested seeds. Before being used in the experiments, seeds had an initial moisture content of $\approx 7 \%$. Increase in weight of imbibed stones and seeds mainly occurred during the first $24 \mathrm{~h}$, respectively corresponding to $70 \%$ and $83 \%$ of the total increase in weight that occurred during the imbibition test. Furthermore, for stones, the increase in weight per hour was highest during the first hour, decreasing exponentially afterward, whereas for seeds, it was highest throughout the first $6 \mathrm{~h}$, also decreasing exponentially afterward. Total weight increase in naked seeds $(45.7 \%)$ was significantly higher than in seeds enclosed by the endocarp $(31.0 \%$; $P=0.0032$ ).

Seed germination. When analyzing the germination percentage for all the data, there was a significant effect of using stones vs. seeds, of the stratification regime, of the incubation temperature, and of growth regulator concentration, and also significant interactions among all of these factors (Table 1). Seeds originated significantly higher germination percentages than stones with a global

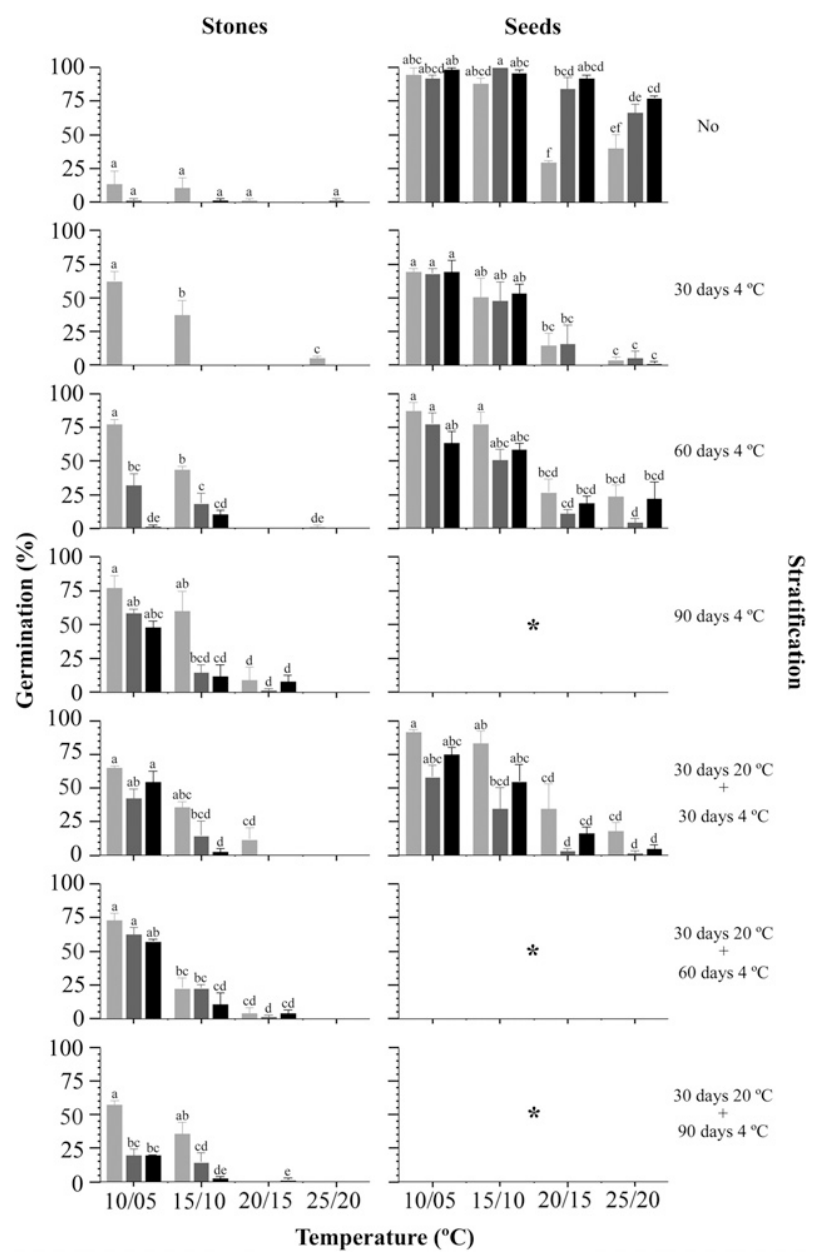

Fig. 1. Germination percentages of stones and seeds of Prunus azorica after 24 weeks with a light period of $12 \mathrm{~h}$. Effect of temperature regime, stratification regime and gibberellin acid $\left(\mathrm{GA}_{3}\right)$ concentration. Temperature (four levels): $10 / 5,15 / 10,20 / 15,25 / 20^{\circ} \mathrm{C}$. Stratification (seven levels): no stratification; 30 to $90 \mathrm{~d}$ at $4{ }^{\circ} \mathrm{C} ; 30 \mathrm{~d}$ at $20^{\circ} \mathrm{C}$ followed by 30 to $90 \mathrm{~d}$ at $4{ }^{\circ} \mathrm{C}$. $\mathrm{GA}_{3}$ concentrations (three levels): water control (light gray); $250 \mathrm{mg} \cdot \mathrm{L}^{-1}$ (dark gray); $500 \mathrm{mg} \cdot \mathrm{L}^{-1}$ (black). Within each chart, significant letters indicate significant differences (Tukey test, applied after analysis of variance, $\alpha=0.05$ ). *Treatments not performed (incubated) as a result of a high germination during stratification ( $75 \%$ to $80 \%)$. 
germination percentage of $49 \% \pm 2.9 \%$ (mean $\pm \mathrm{SE}$ ) and $15 \% \pm 1.5 \%$, respectively (Fig. 1). As a result of this result, subsequent analyses were conducted separately for seeds and stones.

When analyzing results for stones only, there was a significant effect of incubation temperature, stratification regime, and growth regulator concentration on germination percentage as well as interactions between those factors (Table 1). The lowest temperatures tested $\left(15 / 10\right.$ and $\left.10 / 5{ }^{\circ} \mathrm{C}\right)$ originated the highest germination percentages and at these temperatures, all the stratification regimes produced higher germination percentages than the control (no stratification). Increase of growth regulator concentration had a negative effect on germination (Fig. 1). For stones, the maximum germination percentage $(70 \%$ to $80 \%$ ) was attained with cold stratification (60 or $90 \mathrm{~d})$ or with warm $(30 \mathrm{~d})$ followed by cold $(60 \mathrm{~d})$ stratification without the addition of growth regulator at the temperature of $10 / 5{ }^{\circ} \mathrm{C}$ (Fig. 1).

When analyzing results for seeds only, there was a significant effect of incubation temperature, stratification regime, and growth regulator concentration on germination percentage (Table 1). The maximum germination percentage (greater than 90\%) was obtained without stratification or growth regulator addition at $10 / 5$ or $15 / 10{ }^{\circ} \mathrm{C}$.

To better determine the influence of incubation temperature and growth regulator concentration in non-stratified seeds, a more detailed analysis was conducted. Within this group, the germination percentage was significantly affected by incubation temperature $(\mathrm{F}=36.9 ; P<0.001)$ and by growth regulator concentration $(\mathrm{F}=23.6 ; P<0.001)$ with a significant interaction between these two factors $(\mathrm{F}=6.2 ; P<0.001)$. The highest germination percentages were obtained at $10 / 5$ and at $15 / 10^{\circ} \mathrm{C}$, independently of growth regulator addition, and at $20 / 15$ or $25 / 20{ }^{\circ} \mathrm{C}$ with addition of growth regulator (Fig. 1). Analyzing the germination curves for nonstratified seeds, at $10 / 5$ and $15 / 10{ }^{\circ} \mathrm{C}$, there was an acceleration of the germination process with the addition of growth regulator, as shown by a decrease in $\mathrm{T}_{50}$ (Fig. 2). For treatments at $20 / 15$ and $25 / 20{ }^{\circ} \mathrm{C}$, this effect was also observed, and the $\mathrm{T}_{50}$ was even lower than at $10 / 5$ and $15 / 10{ }^{\circ} \mathrm{C}$; however, the germination percentages showed a tendency to decrease at higher temperatures, particularly at $25 / 20^{\circ} \mathrm{C}$ (Fig. 2).

During the stratification process, germination occurred only in seeds (endocarp removed) under $60 \mathrm{~d}$ cold $(\approx 6 \%)$, under $90 \mathrm{~d}$ cold $(\approx 77 \%)$, under $30 \mathrm{~d}$ warm followed by $60 \mathrm{~d}$ cold $(\approx 75 \%)$, and under $30 \mathrm{~d}$ warm followed by $90 \mathrm{~d}$ cold $(\approx 80 \%)$ stratification treatments.

Seedling growth. The time needed for the seedlings to reach the first, second, and third leaf pairs were $9.1( \pm 0.18), 20.1( \pm 0.25)$, and $36.1( \pm 0.41)$ days, respectively, with $100 \%$ survival. Plantlets with the third pair of leaves had a mean length of $5.5( \pm 0.99) \mathrm{cm}$.

\section{Discussion}

The germination percentage of $P$. azorica seeds increased after endocarp removal, which was the most effective treatment in breaking seed dormancy, leading to high germination percentages in a relatively short period of time. This is in accordance with previous work for the genus Prunus (Chen et al., 2007; Grisez et al., 2003). However, in the present study, endocarp removal alone was enough to break dormancy, whereas the same treatment had only shown a partial effect in previous studies.

As expected, imbibition tests showed that in $P$. azorica, the endocarp is not a barrier to water intake by the seed (Grisez, 1974). Although the endocarp might offer some resistance to germination, it is permeable to water; hence, Prunus cannot be considered truly hard-seeded. Still, removal of the endocarp increased germination percentage, which might indicate an inhibitory action of this layer, perhaps related to high levels of abscisic acid, as found in $P$. campanulata (Chen et al., 2007) and in several $P$. persica cultivars (Pawasut et al., 2010). Alternatively, the endocarp might simply work as a mechanical barrier to embryo growth (Nicolaeva, 1977), because P. azorica seeds have a well-developed embryo with large
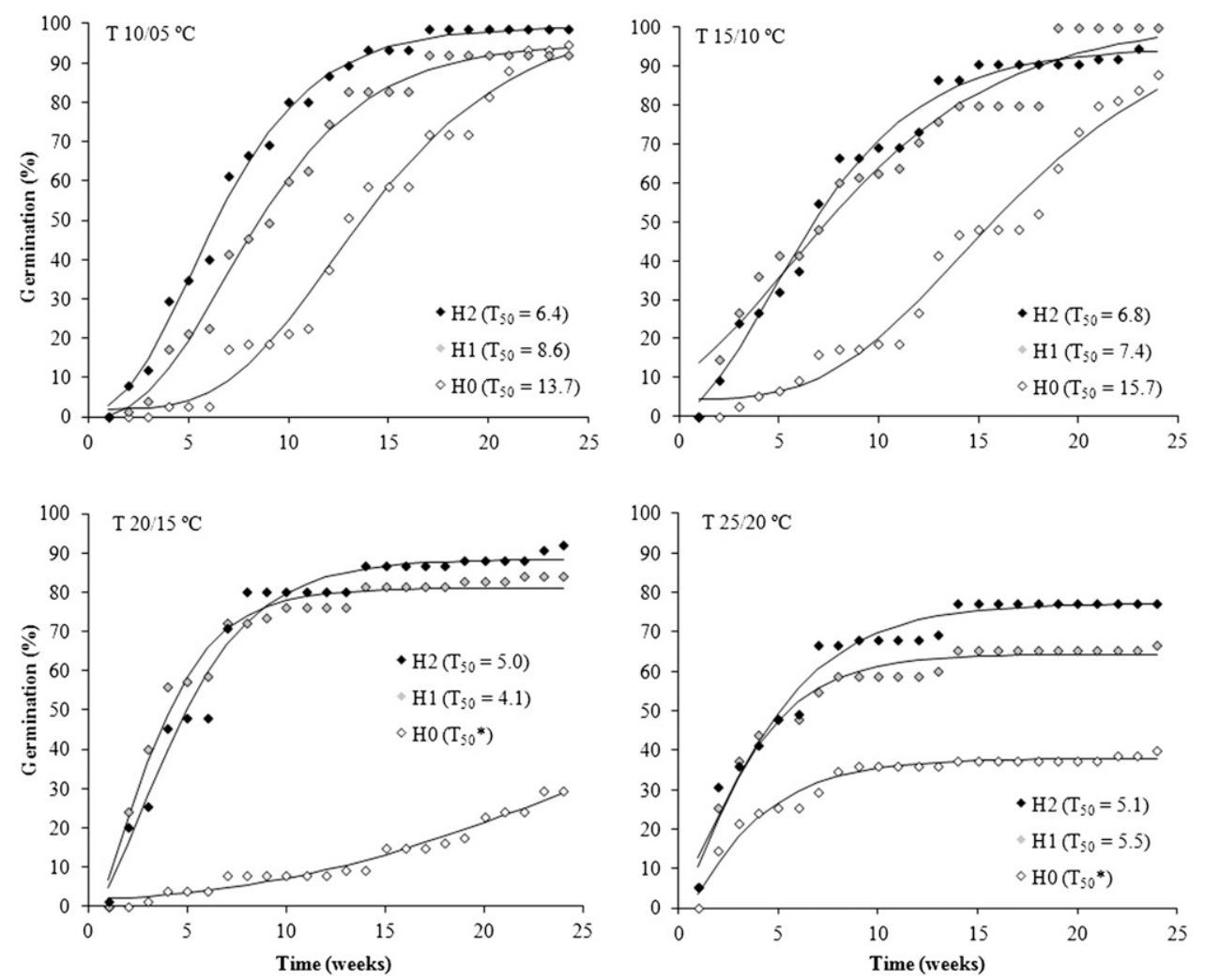

Fig. 2. Accumulated germination curves for non-stratified Prunus azorica seeds during 24 weeks with a light period of $12 \mathrm{~h}$. Effect of four temperature regimes $(10 / 5,15 / 10,20 / 15 \mathrm{C}, 25 / 20)$ and of three gibberellin acid $\left(\mathrm{GA}_{3}\right)$ concentrations (H0, water control; H1, $\left.250 \mathrm{mg} \cdot \mathrm{L}^{-1} ; \mathrm{H} 2,500 \mathrm{mg} \cdot \mathrm{L}^{-1}\right)$. Observed (points) and expected values (lines; estimated by Gompertz model) and $\mathrm{T}_{50}$ (time for $50 \%$ germination in weeks). All models with an $R^{2}$ above 0.9 . *The model would not reach $50 \%$ germination. 
cotyledons that almost completely occupy the space inside the endocarp.

As noted for other Azorean endemic woody taxa (Martins et al., 2012; Moura and Silva, 2010), P. azorica seeds prefer lower temperatures (less than $15^{\circ} \mathrm{C}$ ) to germinate, which is in agreement with the expected temperatures found for the $P$. azorica habitat in the Azores in fall and winter. This is also the case for congeners like $P$. serotina (Phartyal et al., 2009), which germinated best at $10^{\circ} \mathrm{C}$.

Several stratification regimes (including cold or warm followed by cold) increased $P$. azorica seed germination percentage, as expected from previous work (Çetinbas and Koyuncu, 2006; Chen et al., 2007; Esen et al., 2006; Esen et al., 2009; Finch-Savage, 2001; Finch-Savage et al., 2002; Grisez, 1974; Phartyal et al., 2009; Suszka, 1967, 1990). Thus, stratification might be an important factor leading to dormancy break in natural populations, replacing endocarp removal.

According to our results, the addition of $\mathrm{GA}_{3}$ was important only when non-stratified seeds were incubated at relatively high temperatures, which were unfavorable for germination. In those cases, $\mathrm{GA}_{3}$ partly compensated for the negative effect of the high temperatures and increased the germination speed. Gibberellins also increased seed germination in other Prunus species (Çetinbas and Koyuncu, 2006; Chen et al., 2007; Grisez et al., 2003; Phartyal et al., 2009 ) and are generally beneficial in overcoming physiological dormancy in seeds with dormant embryos (Hartmann et al., 1997).

Finally, the present research excluded any type of epicotyl dormancy because after germination, all seedlings readily grew and developed without any particular pre-treatment of cold or warm stratification at an average spring temperature.

Considering the results obtained for the temperatures deemed as favorable for germination and seedling development, physiological dormancy break occurs during fall and winter months and seedlings begin to emerge during spring and summer months, when conditions are suitable for their survival.

Based on seed morphology and on the dormancy-breaking requirements discussed, while following Baskin and Baskin (2004) classification for seed dormancy, P. azorica seeds show a non-deep type of physiological dormancy.

\section{Concluding Remarks}

Our results suggest that $P$. azorica seeds have a non-deep physiological dormancy that can be broken by completely removing of the endocarp and incubating the seeds at $10 / 5$ or $15 / 10{ }^{\circ} \mathrm{C}$ with a light period of $12 \mathrm{~h}$. In natural populations, this is most probably replaced by seasonal variation in temperature, which simulates natural stratification. The high germination percentage obtained with this protocol will allow propagating this species in large quantities in reforestation projects while still preserving the genetic diversity of the populations.

\section{Literature Cited}

Association of Official Seed Analysts. 2007. Tetrazolium Testing Handbook. Ed. J. Peters. (Rosaceae I Revision) 15 Jan. 2012. <http:// www.aosaseed.com/TZwebsite/TZupdateindex. $\mathrm{html}>$.

Azevedo, E.B. 1996. CIELO: Clima insular à escala global. Universidade dos Açores, Angra do Heroísmo. 17 June 2009. <http://www.climaat. angra.uac.pt/cielo $>$.

Barrett, S.C.H. and J. Kohn. 1991. The genetic and evolutionary consequences of small population size in plant: Implications for conservation, p. 3-30. In: Falk, D. and K.E. Holsinger (eds.). Genetics and conservation of rare plants. Oxford University Press, Oxford, CA.

Baskin, C.C. and J.M. Baskin. 1998. Seeds: Ecology, biogeography, and evolution of dormancy and germination. Academic Press, San Diego, CA.

Baskin, J.M. and C.C. Baskin. 2004. A classification system for seed dormancy. Seed Sci. Res. 14:1-16.

Bewley, J.D. and M. Black. 1994. Seeds, physiology, development and germination. 2nd Ed. Plenum Press, New York, NY.

Cardoso, P., P.A.V. Borges, A.C. Costa, R.T Cunha, R. Gabriel, A.M.F. Martins, L. Silva, N. Homem, M. Martins, P. Rodrigues, B. Martins, and E. Mendonça. 2008. A perspectiva arquipelágica-Açores, p. 421-449. In: Martín, J.L., M. Arechavaleta, P.A.V. Borges, and B. Faria (eds.). TOP 100-As cem espécies ameaçadas prioritárias em termos de gestão na região europeia biogeográfica da Macaronésia. Consejería de Medio Ambiente y Ordenación Territorial, Gobierno de Canarias.

Carrera, C., M. Reginato, and S.E. Alomso. 1988. Seed dormancy and germinations in P. mahaleb L. Seed Abstract 11:122.

Çetinbas, M. and F. Koyuncu. 2006. Improving germination of Prunus avium L. seeds by gibberellic acid, potassium nitrate and thiourea. Prague HortScience 33:119-123.

Chen, S.Y., C.T. Chien, J.D. Chung, Y.S. Yang, and S.R. Kuo. 2007. Dormancy-break and germination in seeds of Prunus campanulata (Rosaceae): Role of covering layers and changes in concentration of abscisic acid and gibberellins. Seed Sci. Res. 17:21-32.

Coe, F.M. and R.K. Gerber. 1934. Preliminary studies of the after-ripening and germination of cherry seeds. Arts and Letters Proc. of the Utah Acad. of Sci. 11:185-187.

Crocker, W. and L.V. Barton. 1931. After-ripening, germination, and storage of certain Rosaceous seeds. Contrib. Boyce Thomp. Inst. 3:385-404.

Ellis, R.H., T.D. Hong, and E.H. Roberts. 1985 Handbook of seed technology for genebanks. In: Compendium of specific germination information and test recommendation. Volume II Int. Board for Plant Genetic Resources, Rome, Italy.

Esen, D., N. Günes, and O. Yildiz. 2009. Effects of citric acid presoaking and stratification on germination behavior of Prunus avium L. seed. Pak. J. Bot. 41:2529-2535.

Esen, D., O. Yildiz, E. Cicek, S. Kulac, and C. Kutsal. 2006. Effects of different pretreatments on the germination of different wild cherry (Prunus avium L.) seed sources. Pak. J. Bot. $38: 735-743$.
Fagundo, M. and A. Isidoro. 2004. Propagação das Espécies Lenhosas Endémicas dos Açores. Direcção Regional dos Recursos Florestais. Serv. Florestal do Nordeste.

Finch-Savage, W.E. 2001. Cherry seed. Horticulture research international booklet. Wellesbourne, Warwick, UK.

Finch-Savage, W.E., H.A. Clay, and K.C. Dent. 2002. Seed maturity affects the uniformity of cherry (Prunus avium L.) seed response to dormancy-breaking treatments. Seed Science and Technology 30:483-497.

Flemion, F. 1934. Dwarf seedlings from nonafter-ripened embryos of peach, apple and hawthorne. Contrib. Boyce Thomp. Inst. 6: 205-206.

Giba, Z., D. Grubisic, and R. Konjevic. 1993. The effect of white light, growth regulators and temperature on the germination of blueberry (Vaccinium myrtillus L.) seeds. Seed Science and Technology 21:521-529.

Gompertz, B. 1825. On the nature of the function expressive of the law of human mortality, and on a new mode of determining the value of life contingencies. Philosophical Transaction of the Royal Society 115:513-585.

Grisez, T.J. 1974. Prunus L, p. 658-673. In: Schopmeyer, C.S. (ed.). Seeds of woody plants in the United States. Cherry, peach, and plum. U.S. Department of Agriculture, Washington, DC

Grisez, T.J., J.R. Barbour, and R.P. Karrfalt. 2003. Prunus L. Cherry, peach, and plum. In: Bonner, F.T., tech. coord. Woody plant seed manual. U.S. Department of Agriculture, Forest Service, Washington, DC (Producer). 22 Feb. 2004. <http://wpsm.net/Genera.htm>

Hartmann, H.T., D.E. Kester, F.T. Davies, Jr., and R.L. Geneve. 1997. Plant propagation principles and practices. 6th Ed. Prentice-Hall, Inc., Englewood Cliffs, NJ.

Haut, I.C. 1938. Physiological studies on afterripening and germination of fruit tree seeds. Maryland Agr. Expt. Sta. Bul. 420:1-52.

International Seed Testing Association (ISTA). 1996. International rules for seed testing. Seed Science and Technology 24. Suppl. 335.

Karam, N.S. and M.M. Al-Salem. 2001. Breaking dormancy in Arbutus andrachne L. seeds by stratification and gibberellic acid. Seed Science and Technology 29:51-56.

Laterra, P. and M.E. Bazzalo. 1999. Seed-to-seed allelopathic effects between two invaders of burned pampa grasslands. Weed Res. 39:297308.

Maciel, G.B. 1995. Influência do tempo de conservação das sementes na germinação de espécies vasculares endémicas dos Açores. Bul. Sociedade Broteriana 67:171-186.

Maciel, G.B. 1996. Influência da temperatura e da luz na germinação de espécies vasculares endémicas dos Açores. Açoreana 8:209-218.

Martins, J., O. Moreira, L. Silva, and M. Moura. 2012. Morphophysiological dormancy and germination in seeds of the Azorean tree Picconia azorica. Seed Science and Technology 40:163176.

Martins, M., M. Moura, and L. Silva. 2008. Top 100-Prunus azorica (Hort. Ex Mouil.) Rivas Mart., Lousa Fer. Prieto, E. Dias, J.C. Costa, C. Aguiar. In: Martín, J.L., M. Arechavaleta, P.A.V. Borges, and B. Faria (eds.). Consejería de Medio Ambiente y Ordenación Territorial. Gobierno de Canarias.

Martynez-Gómez, P. and F. Dicenta. 2001. Mechanisms of dormancy in seeds of peach [Prunus persica (L.) Batsch] cv. GF305. Sci. Hort. 91:51-58. 
Moreira, O., J. Martins, L. Silva, and M. Moura. 2009. Propagation of the endangered Azorean cherry Prunus azorica using stem cuttings and air layering. Arquipélago. Life and Marine Sciences 26:9-14.

Moura, M. and L. Silva. 2010. Seed germination of Viburnum treleasei Gand., an Azorean endemic with high ornamental potential. Propagation of Ornamental Plants 10:129-135.

Nicolaeva, M.G. 1969. Physiology of deep dormancy in seeds. Izdatel'stvo Nauka, Leningrad. Translated from Russian by $Z$. Shapiro. National Science Foundation, Washington, DC.

Nicolaeva, M.G. 1977. Factores controlling the seed dormancy pattern, p. 51-74. In: Khan, A.A. (ed.). The physiology and biochemistry of seed dormancy and germination. NorthHolland, Amsterdam, The Netherlands; New York, NY.

Pawasut, A., K. Yamane, N. Fujishige, K. Yoneyama, Y.T. Yamaki, and H. Honjo. 2010. Influence of seed coat removal and chilling on abscisic acid content and germination in ornamental peach (Prunus persica Batsch) seeds. J. Hort. Sci. Biotechnol. 85:248-252.

Phartyal, S.S., S. Godefroid, and N. Koedam. 2009. Seed development and germination ecophysiology of the invasive tree Prunus serotina (Rosaceae) in a temperate forest in Western Europe. Plant Ecol. 204:285-294.

Schäfer, H. 2005. Endemic vascular plants of the Azores: An updated list. Hoppea 66:275-283.
Silva, L., M. Martins, M. Moura, and G.B. Maciel. 2009. Azorean vascular flora: Priorities in conservation. CCPA and Amigos dos Açores.

Suszka, B. 1962. Influence of temperature factor on the breaking of dormancy in mazzard seeds (Prunus avium L.). Arboretum Kornickie 7: 263-268.

Suszka, B. 1967. Studies on dormancy and germination of seed from various species of the genus Prunus L. Arboretum Kornickie 15:129-137.

Suszka, B. 1990. Seeds of Prunus avium - A unique model for research and practice. Spiring og froplantekvalitet hos lignoser. Seminar nr. 180, NJF, Utredning/Rapport 62:17-36

Zar, J.H. 1999. Biostatistical analysis. 4th Ed. Prentice Hall, NJ. 